\title{
How to Reduce the Potential Harmful Effects of Light on Blastocyst Development during IVF
}

\author{
József Bódis ${ }^{a, b}$ Krisztina Gödöny ${ }^{a, b}$ Ákos Várnagy ${ }^{a, b}$ Kálmán Kovács ${ }^{a, b}$ \\ Miklós Koppán ${ }^{\mathrm{a}, \mathrm{b}}$ Bernadett Nagy ${ }^{\mathrm{a}, \mathrm{b}}$ János Erostyák ${ }^{c, d}$ Róbert Herczeg ${ }^{\mathrm{d}}$ \\ Julia Szekeres-Barthó ${ }^{b, d}$ Attila Gyenesei ${ }^{d}$ Gabor L. Kovács ${ }^{b, d, e}$ \\ ${ }^{a}$ Department of Obstetrics and Gynecology, University of Pécs, Pécs, Hungary; ${ }^{b}$ MTA-PTE Human Reproduction

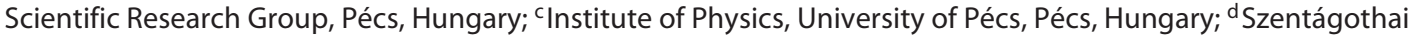 \\ Research Center, Pécs, Hungary; ${ }^{e}$ Department of Laboratory Medicine, University of Pécs, Pécs, Hungary
}

\section{Highlights of the Study}

- The aim of this study was to reduce the potential harmful effects of light exposure during IVF and ICSI.

- The fertilization rate was significantly higher in light-protected ICSI cycles.

- Blastocyst development rates (blastocyst/embryo) were significantly $(p<0.001)$ higher in lightprotected embryos.

- Light protection increases the number of clinical pregnancies/transfers.

\section{Keywords}

IVF · Intracytoplasmic sperm injection · Light protection · Blastocyst development

\begin{abstract}
Purpose: Earlier findings revealed the damaging effect of visible light on zygotes and gametes. The aim of our study is to eliminate or significantly reduce the potentially harmful effects of light exposure during in vitro fertilization (IVF) or intracytoplasmic sperm injection (ICSI) and to investigate the effect of light protection on embryo development and implantation. Materials and Methods: To protect sperm cells, oocytes, and embryos from the potential harmful effects of light exposure during laboratory procedures, we created a dark environment for the cells and applied red filters on laboratory lamps and UV or infrared filters in the micro-
\end{abstract}

scopes in order to eliminate white light exposure of the cells throughout all work stages. Results: The fertilization rate was significantly ( $p=0.011$ ) higher in light-protected ICSI cycles. Blastocyst development rates (blastocyst/embryo) were significantly $(p<0.001)$ higher in light-protected embryos than in those manipulated in conventional light conditions both in IVF (20.9\% difference) and ICSI (38.6\% difference). Numbers of clinical pregnancies/transfers of ICSI fertilized day 5 blastocysts were also significantly ( $p=0.040$ ) higher in light-protected conditions. Conclusions: These data show that light protection has a positive effect on fertilization rate and increases the blastocyst development as well as the number of clinical pregnancies/transfers. Implementation of this light protection method in IVF centers may improve the success rate while maintaining maximal embryo safety.

(C) 2020 The Author(s)

Published by S. Karger AG, Basel karger@karger.com www.karger.com/mpp

Karger $\stackrel{\text { ' }}{5}$

BOPEN ACCESS
(C) 2020 The Author(s)

Published by S. Karger AG, Basel

This is an Open Access article licensed under the Creative Commons Attribution-NonCommercial-4.0 International License (CC BY-NC) (http://www.karger.com/Services/OpenAccessLicense), applicable to the online version of the article only. Usage and distribution for commercial purposes requires written permission.
Bernadett Nagy

Department of Obstetrics and Gynecology

University of Pécs

Édesanyák útja 17, HU-7624 Pécs (Hungary)

bernadett.nagy@aok.pte.hu 


\section{Introduction}

The quality and quantity of embryos and the success rate of assisted reproduction are still not satisfactory and greatly lag behind the theoretically possible success rate. The female reproductive system is able to protect oocytes, sperm cells, and embryos from potential environmental damage, for example, from visible and nonvisible light exposure. During the procedures of assisted reproduction, the gametes, zygotes, and the embryos are subjected to a variable spectrum of light from different sources, including: ambient light, illumination of the safety cabinet, or light emitted from the microscope or the time-lapse imaging cameras $[1,2]$.

IVF (in vitro fertilization), and even more so ICSI (intracytoplasmic sperm injection), expose the cells to light during oocyte retrieval, sperm preparation, fertilization checks, morphological assessment, and embryo transfer.

Light exerts harmful effects on the physiology of mammalian gametes and zygotes $[2,3]$. Previous studies have shown the damaging effect of visible light on oocytes, sperm cells, and embryos [4-7]. It has been suggested that harmful effects of light are associated with the generation of $\mathrm{H}_{2} \mathrm{O}_{2}$ in peroxisomes and mitochondria [5]. Cellular flavins that absorb light $<500 \mathrm{~nm}$ are likely responsible for the generation of reactive oxygen species (ROS) [8]. Light also generates ROS through photochemical processes involving membrane chromophores and oxygen without the involvement of cellular proteins. ROS generation changes the membrane redox state which might lead to membrane channel opening [7]. $\mathrm{H}_{2} \mathrm{O}_{2}$ and its metabolites, hydroxyl radicals, can cause mitochondrial dysfunction and cellular damage [1]. Light may also affect cells via activating stress genes or even damaging DNA directly via ionization [2]. Light-induced photooxidation of culture media may also activate photooxidation of sperm and oocyte lipid membranes resulting in altered membrane structure, which could inhibit fertilization $[2,9]$.

The damaging effect of visible light depends on its spectral composition. The $400-$ to $500-\mathrm{nm}$ range (blue light) is already proven to be orders of magnitude more dangerous than longer wavelengths of the visible spectrum $[1,4,5,10,11]$. Red light $\left(625 \mathrm{~nm}, 0.34 \mathrm{~W} / \mathrm{m}^{2}\right)$ used in the time-lapse incubation system does not decrease the development and quality of blastocysts in either mouse zygotes or parthenogenetically activated porcine embryos [12]. The biological effect of light is wavelength dependent, and, therefore, it is reasonable to assume that the application of filters may reduce the harmful effects of environmental factors in IVF laboratories [13-16].
Our aim is, therefore, to reduce the harmful effects of illumination, thereby minimizing the loss of embryos during gamete manipulation, fertilization, and embryo culture. We compared the outcome of IVF activities between 2 experimental procedures: with and without light protection (540 and 454 patients, respectively). During light protection, we covered the devices used for manipulation during IVF procedures with an aluminum foil and applied red filters on laboratory light sources as well as on the built-in light sources of the microscopes and IVF workstation.

\section{Materials and Methods}

The study was performed between March 1, 2016, and February 28, 2018, in the Assisted Reproduction Unit, Department of Obstetrics and Gynecology, University of Pécs, Hungary. The clinical and laboratory parameters of the patients involved in the 2 procedures are provided in Table 1 . There were no significant differences between the 2 groups regarding baseline clinical characteristics or laboratory data.

\section{Controlled Ovarian Hyperstimulation}

We used the GnRh agonist triptorelin in the course of both long and short protocols. Individual dosages of $\mathrm{rFSH}$, ranging from 150 to $250 \mathrm{IU} /$ day upon the maturity of the follicles were used to carry out stimulation. The starting dose was determined based on the $\mathrm{BMI}$ and age. A maximum daily dose of $300 \mathrm{IU}$ was given to those with a previously detected low response. By using ultrasound examination, we determined the maturity of the follicles from the 6th day of the cycle every other day. Gonadotropin was given individually, based on the size of the follicles. An injection of $250 \mu \mathrm{g}$ $(6,500 \mathrm{IU})$ of human chorionic gonadotropin was administered to induce final oocyte maturation. The aspiration of follicular fluid was carried out $36 \mathrm{~h}$ later using ultrasonography-guided transvaginal puncture under routine intravenous sedation.

\section{Fertilization Procedures}

The fertilization process was either ICSI or IVF, depending on the andrological status (sperm count $<15 \times 10^{6} / \mathrm{mL}$ ), maternal age ( $>35$ years), and the number of previous IVF cycles the patient had undergone before $(>2)$.

Fertilization with ICSI. The oocytes selected for ICSI and denuded with hyaluronidase were checked for maturity. Only metaphase II oocytes showing the presence of the first polar body were selected for fertilization and subjected to ICSI 3-6 h later in the medium G-MOPS ${ }^{\mathrm{TM}}$.

Oocytes not selected for ICSI were fertilized with the IVF method in a bicarbonate-buffered medium (G-IVF ${ }^{\mathrm{TM}}$, Vitrolife ${ }^{\circledR}$, Göteborg, Sweden). Fertilization was checked in medium G-ITM (Vitrolife $^{\circledR}$ ) 24 h later; when oocytes with 2 pronuclei were observed, we defined fertilization as successful. Fertilization rate was calculated based on the total number of oocytes fertilized and the number of oocytes (embryos) with 2 pronuclei. Embryo transfers were carried out 3-5 days after the follicle puncture. We carried out sequential culturing with G-1 $1^{\mathrm{TM}}$ till day 3 (D3), and from D3 to the blastocyst stage we used G-2 $2^{\mathrm{TM}}$. We used premixed gases with standard concentrations $\left(\mathrm{O}_{2}: 5 \%, \mathrm{CO}_{2}: 6 \%\right.$, and $\left.\mathrm{N}_{2}: 89 \%\right)$. 
Table 1. Baseline clinical characteristics and laboratory data of the patients $(n=994)$

\begin{tabular}{lcc}
\hline Characteristics & $\begin{array}{c}\text { Light protection } \\
(n=540)\end{array}$ & $\begin{array}{c}\text { No light protection } \\
(n=454)\end{array}$ \\
\hline Age, years & $36.1 \pm 5.1$ & $35.6 \pm 4.7$ \\
Age distribution, $n(\%)$ & $237(43.9)$ & $206(45.4)$ \\
$\quad<35$ years & $202(37.4)$ & $176(38.7)$ \\
$\quad 36-40$ years & $101(18.7)$ & $72(15.9)$ \\
$\quad>40$ years & $350(64.8)$ & $338(74.4)$ \\
Nulligravida, $n(\%)$ & $428(79.2)$ & $390(85.9)$ \\
Nulliparous, $n(\%)$ & $4.7 \pm 2.6$ & $4.2 \pm 2.1$ \\
Duration of infertility, years & $21.9 \pm 5.8$ & $20.9 \pm 5.3$ \\
BMI, kg/m 2 & & $170(37.4)$ \\
Cause of infertility, $n$ (\%) & $220(40.7)$ & $153(33.7)$ \\
$\quad$ Poor semen quality & $178(33.0)$ & $98(21.6)$ \\
$\quad$ Female factor & $82(15.2)$ & $33(7.3)$ \\
$\quad$ Combined male-female & $60(11.1)$ & $1,845 \pm 1,484$ \\
$\quad$ Unexplained & $1,774 \pm 1,271$ & $1,950 \pm 550$ \\
Serum estradiol on the 6th day of stimulation, pmol/L & $1,875 \pm 425$ & $12 \pm 3$ \\
Total dose of gonadotropin, IU & $12 \pm 3$ & $10.8 \pm 0.9$ \\
Duration of stimulation, days & $11.1 \pm 1.2$ & \\
\hline
\end{tabular}

No significant difference was found between the groups.

Table 2. Illumination levels

\begin{tabular}{lccc}
\hline Operation area & \multicolumn{2}{l}{ Illumination, $\mathrm{lx}$} & \multirow{2}{*}{ Filtering phase } \\
\cline { 2 - 3 } & nonfiltered & filtered & \\
\hline Cell selection, embryo control & & & \\
IVF Workstation 200 Series microscope stage & $1,660(1,330 \pm 330)$ & $525(440 \pm 85)$ & Phase 2 \\
IVF Workstation 200 Series box interior & $500-700$ & $150-210$ & Phase 2 \\
\hline ICSI and IVF & 1,690 & 105 & Phase 3 \\
Nikon Diaphot 200 microscope stage & $300-500$ & $50-100$ & Phase 2 \\
\hline Laboratory free space & & & \\
\hline
\end{tabular}

In the case of day 5 (D5) transfer, morphology was assessed at $114 \mathrm{~h}$. We chose the embryos which reached the blastocyst stage. Blastocysts were evaluated for expansion, inner cell mass development, and trophectoderm appearance using the European Society of Human Reproduction and Embryology scoring system [17]. Blastocyst formation rate was calculated based on the total number of blastocysts with all grades on D5, and the total number of embryos that did not reach the blastocyst stage on D5.

Upon the patient's request, 1,2, or 3 embryos were transferred. The remaining embryos were frozen in compliance with the Hungarian law. A daily dose of $300 \mathrm{mg}$ of progesterone was administered daily to support the luteal phase (Utrogestan; Lab. Besins International S.A. ${ }^{\circledR}$, Paris, France).

The evaluation of the treatment was performed through serum $\beta$-hCG measurements on days 11-14 and transvaginal ultrasound examination 21 days after embryo transfer. We defined biochemi- cal pregnancy as elevated hCG level (>5 IU/L) and clinical pregnancy by the detection of the gestational sac using ultrasonography.

\section{Light Conditions}

Conventional embryo culturing conditions have been improved by using special light filters for the light-protective procedure. Transparent surfaces of the aspiration set and test tube were shielded by aluminum foil (phase 1). During oocyte selection, a red light filter (Lumar Decored SRHPR red foil) was used in the IVF workstation (phase 2). Cells were then cultured as usual in the light-protected incubator. The longest time exposure to maximum intensity of light occurs during the IVF or ICSI. In case of IVF, cells were protected by the colored light filter of the IVF workstation. During the ICSI process, a colored light filter combined with UV and infrared (IR) shielding (phase 3) in the micromanipulation 
Table 3. Fertilization rates in IVF and ICSI fertilization

$\begin{array}{ll}\begin{array}{l}\text { Light protection } \\ (n=540)\end{array} & \begin{array}{l}\text { No light protection } \\ (n=454)\end{array}\end{array}$

IVF

$\begin{array}{lcr}\text { Fertilized oocytes, } n & 2,123 & 1,394 \\ \text { Produced embryos, } n & 1,348 & 915 \\ \text { Fertilization rate, \% } & 63.5 & 65.6 \\ \text { Odds ratio } & 0.911 & \\ \text { Confidence interval } & 0.790-1.049 & \\ \text { p value } & 0.196 & \end{array}$

\section{ICSI fertilization}

$\begin{array}{lcr}\text { Fertilized oocytes, } n & 2,000 & 1,509 \\ \text { Embryos produced, } n & 1,149 & 802 \\ \text { Fertilization rate, \% } & 57.5 & 53.1 \\ \text { Odds ratio } & 1.190 & \\ \text { Confidence interval } & 1.040-1.362 & \\ p \text { value } & 0.011 & \end{array}$

Fertilization rate, proportion of injected oocytes with 2 pronuclei on the day after injection.

workstation was used for this purpose. The control of the embryos during the time of culturing and their preparation for transfer was done using phase 2 protection. Laser-assisted hatching, when needed, was performed under phase 3 protection. This IR blocker prevents cells in the manipulation zone from local overheating by the focused, longer wavelength IR light of the microscope.

Brightness (lx values) has been measured using a calibrated Extech SDL 400-NIST light meter (Table 2). Filtering results not only in a different spectral range of light but also in a lower light intensity. In the laboratory, we used red-filtered ceiling light throughout all embryo manipulation procedures. The mean total manipulation time was 1,556.4 s (range: 1,369-2,198 s, SD: $252.2 \mathrm{~s}$ ) during IVF and 3,227.4 s (range: 2,749-4,298 s, SD: $446.2 \mathrm{~s}$ ) during the ICSI procedure. Ten embryos were taken out from the incubator for ICSI. The check of embryo development lasted $183.9 \mathrm{~s}$ (range: 162-202 s, SD: $14.2 \mathrm{~s})$.

\section{Statistical Analysis}

To determine statistically significant differences, odds ratios (OR) and 95\% confidence interval were calculated. Differences were considered to be significant at $p<0.05$.

\section{Results}

\section{Fertilization Rate}

The fertilization rate during ICSI was significantly higher $(p<0.05)$ when the light protection protocol was used $(57.5 \%)$ compared with the conventional method (53.1\%). There was no significant difference between the 2 groups in the fertilization rate during IVF (Table 3 ).

Decreased Light Effect on Blastocyst

Development
Table 4. Blastocyst development in IVF and ICSI fertilization

\begin{tabular}{lcc}
\hline & $\begin{array}{l}\text { Light } \\
\text { protection } \\
(n=540)\end{array}$ & $\begin{array}{l}\text { No light } \\
\text { protection } \\
(n=454)\end{array}$ \\
\hline IVF procedure & & \\
5th day embryos, total $n$ & 823 & 459 \\
Blastocysts produced, $n$ & 393 & 123 \\
Blastocyst development rate, \% & 47.7 & 26.8 \\
Odds ratio & 2.497 & \\
Confidence interval & $1.949-3.199$ & \\
$p$ value & $1.903 \times 10^{-12}$ & \\
\hline ICSI fertilization & & \\
5th day embryos, total $n$ & 657 & 464 \\
Blastocysts produced, $n$ & 462 & 147 \\
Blastocyst development rate, \% & 70.3 & 31.7 \\
Odds ratio & 5.109 & \\
Confidence interval & $3.950-6.609$ & \\
$p$ value & $1.866 \times 10^{-32}$ & \\
\hline
\end{tabular}

Blastocyst development rate, blastocysts/embryos.

Table 5. Number of clinical pregnancies/transfers in IVF and ICSI

\begin{tabular}{llc}
\hline & $\begin{array}{l}\text { Light } \\
\text { protection } \\
(n=540)\end{array}$ & $\begin{array}{l}\text { No light } \\
\text { protection } \\
(n=454)\end{array}$ \\
\hline IVF (5th day transfer) & & \\
Embryo transfers, $n$ & 117 & 72 \\
Pregnancies, $n$ & 45 & 22 \\
Clinical pregnancies/transfers, \% & 38.5 & 30.6 \\
Odds ratio & 1.420 & \\
Confidence interval & $0.761-2.653$ & \\
p value & 0.274 & \\
\hline ICSI fertilization (5th day transfer) & & \\
Embryo transfers, $n$ & 172 & 158 \\
Pregnancies, $n$ & 53 & 20.9 \\
Clinical pregnancies/transfers, \% & 30.8 & \\
Odds ratio & 1.687 & \\
Confidence interval & $1.021-2.787$ & \\
p value & 0.040 & \\
\hline
\end{tabular}

\section{Blastocyst Development}

The blastocyst development rate by D5 is the most important embryological outcome of assisted reproduction.

The difference between the blastocyst development rate of light-protected and conventionally manipulated embryos was highly significant both in IVF and ICSI groups (Table 4). In IVF, the blastocyst development rate was sig- 
nificantly higher in the light-protected group than in the group handled under conventional conditions (47.7 vs. $26.8 \%$, respectively; $p<0.001$ ). During ICSI, 462 blastocysts developed from the 657 five-day-old embryos (blastocyst development rate: $70.3 \%$ ), while under conventional conditions the blastocyst development rate was only $31.7 \%$ ( $p<0.001$, online suppl. Fig. 1; for all online suppl. material, see www.karger.com/doi/10.1159/000509016).

\section{Number of Clinical Pregnancies/Transfers}

The number of clinical pregnancies/transfers (the number of gestational sacs observed/the number of transferred embryos) is the most important clinical outcome measure of embryo transfer. Transfer of light-protected D5 embryos resulted in a significantly higher number of clinical pregnancies/transfers $(p<0.05 ; 30.8 \%)$ than that observed in the conventional group (20.9\%) after the ICSI procedure (Table 5; online suppl. Fig. 2). In the case of conventional IVF, the difference between the number of clinical pregnancies/transfers of light-protected and conventionally manipulated embryos was not significant (online suppl. Fig. 3).

\section{Discussion}

This study focuses on the potential positive impact of light protection of gametes and zygotes on success rates of assisted reproductive technology. Our aim was to eliminate - or significantly reduce - the harmful effects of illumination [18], thereby minimizing the loss of embryos during manipulation. To achieve this, we applied light protection during all the work stages by covering the devices with aluminum foil and using red color filters on laboratory (ceiling light) and instrument light sources, along with UV filters in the microscopes.

Both in ICSI and IVF procedures, a significantly higher number of light-protected fertilized oocytes reached the blastocyst stage compared to those manipulated under normal light conditions. Furthermore, the numbers of clinical pregnancies/transfers of light-protected D5 ICSI embryos were significantly higher than in the nonprotected ICSI group. Our results show that the harmful effects of light exposure can be significantly reduced by the use of red filters. The difference between the 2 procedures explains that while light protection did not result in significant improvement in either the fertilization or number of clinical pregnancies/transfers of IVF embryos, both of these parameters were significantly better in lightprotected ICSI embryos than in the controls. Based on our results, the unfavorable effect of light exposure during the longer ICSI procedure (mean manipulation time difference is 1,671 s) appears to be obvious. During this study, we did not use embryoscopes; further research is needed to evaluate the potential use of filters in a timelapse system.

Artificial culture conditions still cannot fully replace the natural environment within the female genital tract [19]. Because of the significant (approximately 60\%) embryo loss, we need to eliminate or at least minimize the harmful effects during the manipulation. Bognar et al. [20], showed that light exposure significantly reduced the implantation capacity of mouse embryos, and that the harmful effect was related to the wavelength rather than to the brightness of the light. Previous studies have shown that not only UV radiation but also visible light is toxic to mammalian cells. Irradiation of cultured mouse, monkey, and human cells with violet $(400-450 \mathrm{~nm})$ or blue (450-490 nm) light induced $\mathrm{H}_{2} \mathrm{O}_{2}$ production in peroxisomes and in mitochondria and caused DNA damage $[5,18]$. During the final stages of follicular growth, the oocyte may be sensitive to damage by ROS following environmental stress [4, 21-23]. Rabbit, hamster, bovine, and mouse embryos are also sensitive to light $[6,24-26]$.

Despite these facts, only a few recommendations can be found in the literature. First Hirao and Yanagimachi [4] have found that in the case of hamster eggs, the fluorescent light is more harmful than the light from an incandescent lamp, and they recommended the use of red cellophane filter in 1978. Testart et al. [27] described an incubator in which culture tubes were stored in metal buckets in order to provide a dark environment [13]. In 1990, Findley et al. [13] described an incubator where the ambient light was controlled. Noda et al. [14] used low illumination through embryo manipulation, which provided a relatively high blastulation rate.

Although IVF has revolutionized infertility treatment, during manipulation the embryo is subjected to environmental stressors [28-30]. Our maximal care about the lighting applied in IVF and ICSI procedures is expected to ensure a safe environment. We have found that protecting the embryos from unnecessary illumination results in higher fertility and blastocyst formation rates, and a higher number of clinical pregnancies/transfers on D5. Although these results are promising, further investigations are needed to check the live birth rate after lightprotected IVF and ICSI. Light protection has increased the number of embryos, and thus more embryos have been frozen than before. 


\section{Conclusions}

Visible light, especially in the blue spectrum, is an environmental factor that should be considered during handling and transporting germ cells and embryos in IVF laboratories. In addition to the positive changes in the fertilization rate, light protection also increased the number of embryos, and thus more frozen embryos were available for further transfers. Based on our findings, the use of redfiltered light is recommended throughout the procedure. Based on the results of this pilot clinical study, we are pursuing further detailed investigations to elucidate the biological background of our observation. Implementation of this light protection method in IVF centers may improve success rates providing maximal embryo safety.

\section{Acknowledgments}

Experiments were partially supported by the NKFI-6 (The National Research, Development and Innovation Office) grant No. 115394 (Hungary) and MTA-PTE Human Reproduction Scientific Research Group. This work was also supported by the GINOP-2.3.2-15-2016-00021 grant "The use of chip-technology in increasing the effectiveness of human in vitro fertilization."

\section{Statement of Ethics}

All procedures performed in studies involving human participants were in accordance with the ethical standards of the institutional and/or national research committee and with the $1964 \mathrm{Hel}-$ sinki Declaration and its later amendments or comparable ethical standards. The study was approved by the Regional Research Ethics Committee of the Medical Center, University of Pécs, Hungary (No. 6654. PTE 2017). Informed consent was signed by every individual patient before the initiation of any medical investigation or intervention. The research had institutional review board approval.

\section{Conflict of Interest Statement}

The authors declare that they have no conflicts of interest.

\section{Author Contributions}

J.B., G.L.K., and K.G.: study design; Á.V., K.K., J.E., and K.G.: data collection; A.G. and R.H.: statistical analysis; J.B., M.K., J.S.-B., and A.G.: data interpretation; J.B., B.N., Á.V., and J.E.: manuscript preparation; B.N.: literature search; and J.B.: fund collection.

\section{References}

1 Ottosen LD, Hindkjaer J, Ingerslev J. Light exposure of the ovum and preimplantation embryo during ART procedures. J Assist Reprod Genet. 2007 Feb-Mar;24(2-3):99-103.

2 Pomeroy KR. The effect of light on embryos and embryo culture. J Reprod Biotechnol Fertil. 2013;3(2):46-54.

3 Nematollahi-mahani SN, Pahang H, Moshkdanian G, Nematollahi-mahani A. Effect of embryonic fibroblast cell co-culture on development of mouse embryos following exposure to visible light. J Assist Reprod Genet. 2009 Mar;26(2-3):129-35.

4 Hirao Y, Yanagimachi R. Detrimental effect of visible light on meiosis of mammalian eggs in vitro. J Exp Zool. 1978 Dec;206(3):365-9.

5 Hockberger PE, Skimina TA, Centonze VE, Lavin C, Chu S, Dadras S, et al. Activation of flavin-containing oxidases underlies light-induced production of $\mathrm{H} 2 \mathrm{O} 2$ in mammalian cells. Proc Natl Acad Sci USA. 1999 May; 96(11):6255-60.

6 Oh SJ, Gong SP, Lee ST, Lee EJ, Lim JM. Light intensity and wavelength during embryo manipulation are important factors for maintaining viability of preimplantation embryos in vitro. Fertil Steril. 2007 Oct;88(4 Suppl): $1150-7$.

7 Lavi R, Ankri R, Sinyakov M, Eichler M, Friedmann H, Shainberg A, et al. The plasma membrane is involved in the visible light-tissue interaction. Photomed Laser Surg. 2012 Jan;30(1):14-9.

8 Eichler M, Lavi R, Shainberg A, Lubart R. Flavins are source of visible-light-induced free radical formation in cells. Lasers Surg Med. 2005 Oct;37(4):314-9.

9 Otsuki J, Nagai Y, Chiba K. Damage of embryo development caused by peroxidized mineral oil and its association with albumin in culture. Fertil Steril. 2009 May;91(5): $1745-9$.

10 Squirrell JM, Wokosin DL, White JG, Bavister $\mathrm{BD}$. Long-term two-photon fluorescence imaging of mammalian embryos without compromising viability. Nat Biotechnol. 1999 Aug;17(8):763-7.

11 Zhang YP, Li SR, Ping J, Li SW, Zhou HB, Sun BJ, et al. The effects of light exposure during incubation on embryonic development and hatchling traits in lizards. Sci Rep. 2016 Dec; 6(1):38527.

12 Li R, Pedersen KS, Liu Y, Pedersen HS, Lægdsmand M, Rickelt LF, et al. Effect of red light on the development and quality of mammalian embryos. J Assist Reprod Genet. 2014 Jul;31(7):795-801.

13 Findley WG. Environmentally controlled in vitro incubator. US Patent 1990;no US4892830.
14 Noda Y, Goto Y, Umaoka Y, Shiotani M, Nakayama T, Mori T. Culture of human embryos in alpha modification of Eagle's medium under low oxygen tension and low illumination. Fertil Steril. 1994 Nov;62(5): 1022-7.

15 KO P. M R. The Effect of Light on Embryos and Embryo Culture. In: Kay Elder MVdB, Bryan Woodward, editor. Troubleshooting and problem-solving in the IVF laboratory 2014. pp. 104-17.

16 Li R, Liu Y, Pedersen HS, Callesen H. Effect of ambient light exposure of media and embryos on development and quality of porcine parthenogenetically activated embryos. Zygote. 2015 Jun;23(3):378-83.

17 Balaban B, Brison D, Calderon G, Catt J, Conaghan J, Cowan L, et al.; Alpha Scientists in Reproductive Medicine and ESHRE Special Interest Group of Embryology. The Istanbul consensus workshop on embryo assessment: proceedings of an expert meeting. Hum Reprod. 2011 Jun;26(6):1270-83.

18 Wang RJ. Lethal effect of "daylight" fluorescent light on human cells in tissue-culture medium. Photochem Photobiol. 1975 May; 21(5):373-5.

19 Bavister BD. Interactions between embryos and the culture milieu. Theriogenology. 2000 Jan;53(2):619-26. 
20 Bognar Z, Csabai TJ, Pallinger E, Balassa T, Farkas N, Schmidt J, et al. The effect of light exposure on the cleavage rate and implantation capacity of preimplantation murine embryos. J Reprod Immunol. 2019 Apr;132: 21-8.

21 Zenzes MT, Puy LA, Bielecki R. Immunodetection of benzo[a]pyrene adducts in ovarian cells of women exposed to cigarette smoke. Mol Hum Reprod. 1998 Feb;4(2): $159-65$.

22 Ménézo Y, Dale B, Cohen M. DNA damage and repair in human oocytes and embryos: a review. Zygote. 2010 Nov;18(4):357-65.

23 Daniel JC Jr. Clevage of Mammalian Ova Inhibited by Visible Light. Nature. 1964 Jan; 201(4916):316-7.
24 Schumacher A, Fischer B. Influence of visible light and room temperature on cell proliferation in preimplantation rabbit embryos. J Reprod Fertil. 1988 Sep;84(1):197204.

25 Takenaka M, Horiuchi T, Yanagimachi R. Effects of light on development of mammalian zygotes. Proc Natl Acad Sci USA. 2007 Sep; 104(36):14289-93.

26 Korhonen K, Sjövall S, Viitanen J, Ketoja E, Makarevich A, Peippo J. Viability of bovine embryos following exposure to the green filtered or wider bandwidth light during in vitro embryo production. Hum Reprod. 2009 Feb; 24(2):308-14.
27 Testart J, Lassalle B, Frydman R. Apparatus for the in vitro fertilization and culture of human oocytes. Fertil Steril. 1982 Sep;38(3): 372-5.

28 Umaoka Y, Noda Y, Nakayama T, Narimoto K, Mori T, Iritani A. Effect of visual light on in vitro embryonic development in the hamster. Theriogenology. 1992 Dec;38(6):104354.

29 Boone WR H, Johnson JE. Quality management issues in the assisted reproduction laboratory. J Reprod Stem Cell Biotechnol. 201; 1(1):30-107.

30 Wale PL, Gardner DK. The effects of chemical and physical factors on mammalian embryo culture and their importance for the practice of assisted human reproduction. Hum Reprod Update. 2016 Jan-Feb;22(1):2-22. 